\title{
Research
}

\section{Prevalence of systolic inter-arm differences in blood pressure for different primary care populations:}

\author{
systematic review and meta-analysis
}

\begin{abstract}
Background

Various prevalence figures have been reported for inter-arm differences in blood pressure (IAD); variation may be explained by differing population vascular risk and by measurement method.
\end{abstract}

\section{Aim}

To review the literature to derive robust estimates of IAD prevalence relevant to community populations.

\section{Design and setting}

Systematic review and meta-analysis.

\section{Method}

MEDLINE, Embase, and CINAHL were searched for cross-sectional studies likely to represent general or primary care populations, reporting prevalence of IAD and employing a simultaneous method of measurement. Using study-level data, pooled estimates of mean prevalence of systolic IADs were calculated and compared using a random effects model.

\section{Results}

Eighty IAD studies were identified. Sixteen met inclusion criteria: pooled estimates of prevalence for systolic IAD $\geq 10 \mathrm{mmHg}$ were $11.2 \%(95 \%$ confidence interval $[\mathrm{Cl}]=9.1$ to $13.6)$ in hypertension, $7.4 \%(95 \% \mathrm{Cl}=5.8$ to 9.2) in diabetes, and $3.6 \%(95 \% \mathrm{Cl}=2.3$ to 5.0$)$ for a general adult population $(P<0.001$ for subgroup differences). Differences persisted for higher cut-off values. Prevalences were lower for East Asian than for Western populations and were overestimated by sequential measurement where this could be compared with simultaneous measurement within studies (relative risk for IAD: $2.9[95 \% \mathrm{Cl}=2.1$ to 4.1$]$ ]). Studies with higher mean absolute systolic pressures had higher prevalences for a systolic IAD $\geq 10 \mathrm{mmHg}(P=0.04)$

\section{Conclusion}

Prevalences of IADs rise in relation to underlying cardiovascular comorbidities of the population studied, and are overestimated threefold when sequential measurement is used. Population-specific variation in prevalences of IAD should be taken into accoun in delivering clinical care and in planning future studies.

\section{Keywords}

blood pressure determination; hypertension; prevalence; inter-arm difference; primary care.

\section{INTRODUCTION}

A difference in blood pressure measurements between arms has been reported in cohorts with hypertension, ${ }^{1-4}$ diabetes, ${ }^{5-7}$ chronic kidney disease, $, 8,9$ or peripheral arterial disease. ${ }^{10}$ Differences are also reported for populations free of chronic disease..$^{6,11-15}$ Inter-arm differences in blood pressure can cause errors in blood pressure interpretation and management when not recognised; 2, 2, 16-18 they are also associated with increased cardiovascular mortality and morbidity. ${ }^{19-21}$

The reported prevalences of inter-arm differences vary greatly; they are usually higher in the presence of hypertension.,22,23 The majority of reports are based on selected or convenience samples, usually in a secondary care setting; fewer studies have addressed the subject in populations relevant to primary care. $4,5,13,14,24$ However, a recent systematic review indicated that prevalence figures are lower in community than in outpatient or inpatient hospital settings. ${ }^{25}$

Current guidelines advise that blood pressure should be checked in both arms when assessing patients for hypertension, but this is often not done by GPs. ${ }^{26,27}$ Knowledge of the prevalence of an inter-arm difference in primary or community care settings allows estimation of the frequency with which, for example, a blood pressure measurement may be underestimated by $\geq 10 \mathrm{mmHg}-\mathrm{a}$ clinically important error affecting diagnosis

CE Clark, PhD, FRCP, FRCGP, clinical senior lecturer; RS Taylor, $\mathrm{PhD}$, professor in health services research; JL Campbell, MD, FRCGP, professor of general practice and primary care, Primary Care Research Group, University of Exeter Medical School, Exeter. AC Shore, PhD, professor of cardiovascular science, NIHR Exeter Clinical Research Facility, Royal Devon and Exeter Hospital and Institute of Biomedical and Clinical Science, University of Exeter Medical School, Exeter.

\section{Address for correspondence}

Christopher E Clark, Primary Care Research and treatment decisions - if a difference has not been excluded. It can also indicate the likely workload required to confirm the existence of suspected differences. Prevalence is overestimated when a robust repeated simultaneous measurement technique is not used, ${ }^{2,28}$ and current guidelines advise that such confirmation requires simultaneous assessment. 26,29

This systematic review and metaanalysis was undertaken to derive estimates of the prevalence, measured by simultaneous assessment, of systolic interarm differences in populations relevant to primary care settings.

\section{METHOD}

MEDLINE, Embase, and CINAHL databases were searched from their respective commencement dates to 12 November 2014 using search terms refined from previous systematic reviews (Appendix 1). 2,20 Further studies were identified from personal archives and checking of reference lists for included studies. Full texts were retrieved for any studies reporting on interarm differences in blood pressure. Studies were eligible for inclusion if they employed a repeated simultaneous blood pressure measurement protocol, and examined a population likely to represent a general practice or primary care population. No directly relevant quality assessment tool for included studies was identified. However, application of the inclusion criteria for the
Group, University of Exeter Medical School, Smeall Building, St Luke's Campus, Magdalen Road, Exeter, Devon, EX1 2LU, UK.

E-mail: c.e.clark@exeter.ac.uk

Submitted: 24 May 2016; Editor's response: 4 July 2016; final acceptance: 18 August 2016. (CBritish Journal of General Practice

This is the full-length article (published online 11 Oct 2016) of an abridged version published in print. Cite this version as: Br J Gen Pract 2016; DOI: 10.3399/bjgp16X687553 


\section{How this fits in}

Reported prevalence figures for inter-arm differences in blood pressure vary greatly between studies. Much variation can be explained by different underlying population vascular risks. Relevant prevalence figures for primary care are not well described. This study presents robust estimates of inter-arm difference prevalence applicable to general practice populations. Community prevalences are lower than reported for hospital cohorts but rise in relation to the underlying cardiovascular comorbidities of the population studied. Prevalences are overestimated threefold when sequential measurement is used.

method of blood pressure measurement and sampling of the population ensured that study quality for the outcome of interest was standardised.

Study populations were classified as hypertensive, diabetic, or general. Cohorts were included within the general population category unless specifically selected by diabetic or hypertensive status, thus being considered representative of a

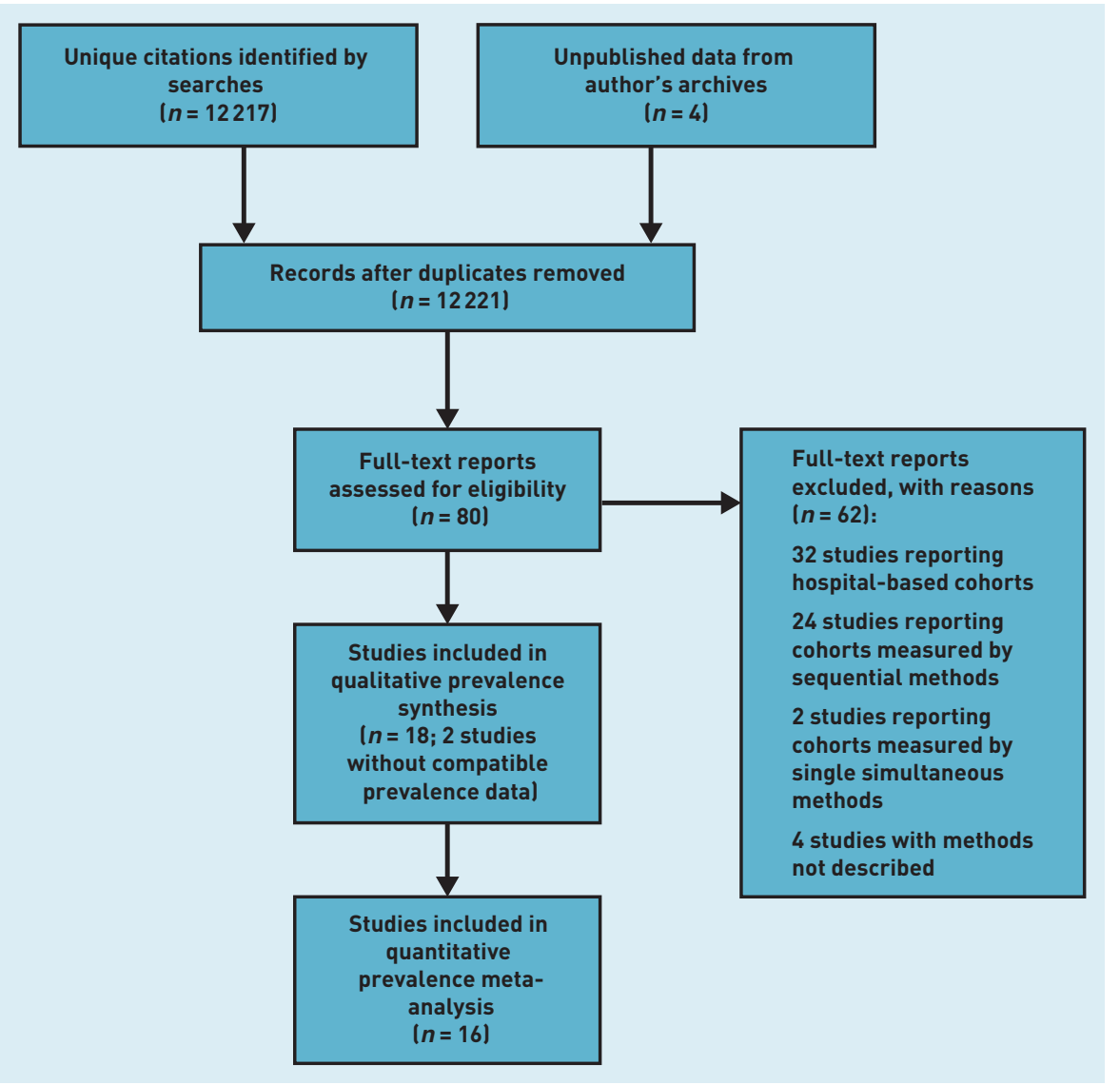

general primary care population. Where mixed cohorts were reported, authors were contacted to clarify appropriate classification and request subgroup prevalence data.

Study-level prevalence datawere extracted from included studies for systolic interarm differences $\geq 10 \mathrm{mmHg}, \geq 15 \mathrm{mmHg}$, and $\geq 20 \mathrm{mmHg}$. Pooled estimates of mean prevalences for systolic inter-arm differences $\geq 10 \mathrm{mmHg}, \geq 15 \mathrm{mmHg}$, and $\geq 20 \mathrm{mmHg}$ were calculated and compared between populations using meta-analysis of proportions undertaken in Stata (version 12.1) with the 'metaprop' command. A random effects model was chosen due to potential clinical heterogeneity of included studies. Statistical heterogeneity was assessed using the $R^{2}$ statistic and, where present, explored with sensitivity analyses based on ethnic origin, or methodology. Univariable and multivariable metaregression analyses were undertaken to examine the association between various study-level factors (mean age, percentage of males, mean absolute systolic blood pressure, setting [community versus clinic], country of conduct, and indication [hypertensive versus diabetic versus general population]), and the prevalence for systolic inter-arm differences $\geq 10 \mathrm{mmHg}$. The 'permute' option for the 'metareg' command in Stata was used to allow for multiple testing.

Where studies also reported prevalence of blood pressure differences based on sequential measurements, these data were also extracted for comparison. Differences in aggregate study prevalence were estimated for the simultaneous versus sequential methods after adjustment for withinperson correlations reported elsewhere, ${ }^{30}$ according to Cochrane Review methods. ${ }^{31,32}$ Results are expressed as relative risks of diagnosing an inter-arm difference for sequential versus simultaneous assessment and pooled using random effects meta-analysis. Potential publication bias was assessed using funnel plots and the Egger test. ${ }^{33}$

\section{RESULTS}

Searches identified 12217 unique citations; 80 full texts were reviewed, and 18 studies met the inclusion criteria. One study reported no prevalence data in a form that could be included in the analysis, ${ }^{34}$ and another that rounded inter-arm differences to the nearest $5 \mathrm{mmHg}$ was excluded. ${ }^{10}$ Thus 16 studies (comprising 21 subgroups) contributed data to the meta-analyses (Figure 1, Table 1).

Pooled prevalences of a systolic inter- 
Table 1. Studies included in analyses

\section{Study}

[country of origin]

Harrison et al $1960^{35}$ (US)

Orme et al $1999^{44}$ (UK)

Kimura et al $2004^{36}$ (Japan) Participants in community check-up

for arteriosclerosis, age 62.4 years $(11.1 ; 338$ male, 702 female)

Karagiannis et al $2005^{17}$

(Greece)

Hospital staff, visitors, and patients,

mean age 54 years (18.3),

$195(50.8 \%)$ female

Clark et al $2007^{3}(\mathrm{UK})^{\mathrm{a}} \quad$ Primary care hypertensive patients, age 69.6 years (9.7), 40 male

Kleefstra et al $2007^{7}$

(Netherlands)

Patients with type 2 diabetes mellitus

Clark et al $2009^{5}$ (UK)

Lohmann et al $2011^{37}$

(Germany)

Fonseca-Reyes et al 2012

(Mexico)

Kim 201343 (Korea) $\quad \begin{aligned} & \text { Adult family medicine clinic } \\ & \text { patients age }>40 \text { years free }\end{aligned}$

patients age $>40$ years free of

cardiovascular and renal disease

200 (43\%) with hypertension

\begin{tabular}{|c|c|c|c|c|}
\hline $\begin{array}{l}\text { Okada et al } 2013^{41} \\
\text { (Japan) }\end{array}$ & $\begin{array}{l}\text { Consecutive patients with type } 2 \text { diabetes } \\
\text { in outpatient clinic }\end{array}$ & $\begin{array}{l}\text { Simultaneous four-limb measurement } \\
\text { (COLIN waveform analyser, device not stated). }\end{array}$ & 314 & $5.1 \% \geq 10 \mathrm{mmHg}$ \\
\hline $\begin{array}{l}\text { Sheng et al } 2013^{38} \\
\text { (China) }^{a}\end{array}$ & $\begin{array}{l}\text { Older Chinese (age }>60 \text { years), } \\
1895(60.5 \%) \text { with hypertension } \\
\text { and } 285(9.2 \%) \text { with diabetes }\end{array}$ & $\begin{array}{l}\text { Simultaneous four-limb machine; } \\
\text { ABI-form device (COLIN VP1000) }\end{array}$ & 3133 & $\begin{array}{l}6.4 \% \geq 10 \mathrm{mmHg} \\
1.8 \% \geq 15 \mathrm{mmHg}\end{array}$ \\
\hline $\begin{array}{l}\text { Van der Hoeven et al } 2013^{45} \\
\text { (Netherlands) }^{a}\end{array}$ & $\begin{array}{l}\text { Staff patients and visitors to hypertension } \\
\text { clinic comparing sequential and } \\
\text { simultaneous measures; } \\
132 / 240(55 \%) \text { with hypertension }\end{array}$ & $\begin{array}{l}\text { Mean of three simultaneous } \\
\text { repeated measures; } \\
\text { Microlife Watch BP® Office }\end{array}$ & 240 & $\begin{array}{l}11.7 \% \geq 10 \mathrm{mmHg} \\
5.0 \% \geq 15 \mathrm{mmHg} \\
1.6 \% \geq 20 \mathrm{mmHg}\end{array}$ \\
\hline $\begin{array}{l}\text { Canepa et al } 2013^{42} \\
\text { (US) }\end{array}$ & $\begin{array}{l}\text { Community sample free of } \\
\text { diabetes, stroke, or heart disease } \\
\text { at recruitment - the Baltimore } \\
\text { Longitudinal Study of Ageing }\end{array}$ & $\begin{array}{l}\text { Mean of second and third simultaneous } \\
\text { pairs of readings with four-limb } \\
\text { device COLIN VP2000 }\end{array}$ & 1045 & $\begin{array}{l}4.8 \% \geq 10 \mathrm{mmHg} \\
1.1 \% \geq 15 \mathrm{mmHg}\end{array}$ \\
\hline Clark et al 2014a'b (UK)a & $\begin{array}{l}\text { Community cohorts with and } \\
\text { without diabetes recruited to } \\
\text { the Diabetes Alliance for Research } \\
\text { in England (DARE) }\end{array}$ & $\begin{array}{l}\text { Two Omron HEM } 705 \mathrm{CP} \text { in } \\
\text { simultaneous } 2 \times 2 \text { crossover } \\
\text { design; mean of four pairs } \\
\text { of readings }\end{array}$ & $\begin{array}{l}514 \text { (diabetes) } \\
286 \text { (control) }\end{array}$ & $\begin{array}{l}8.6 \% \geq 10 \mathrm{mmHg} \\
2.3 \% \geq 15 \mathrm{mmHg} \\
2.9 \% \geq 10 \mathrm{mmHg} \\
0.4 \% \geq 15 \mathrm{mmHg}\end{array}$ \\
\hline Clark et al 2014b40 (UK) & $\begin{array}{l}\text { Community cohorts with and } \\
\text { without diabetes and hypertension }\end{array}$ & $\begin{array}{l}\text { Two Omron HEM } 705 \mathrm{CP} \text { in } \\
\text { simultaneous } 2 \times 3 \text { crossover } \\
\text { design; mean of six pairs of readings }\end{array}$ & $\begin{array}{l}265 \text { (diabetes) } \\
116 \text { (control) }\end{array}$ & $\begin{array}{c}5.2 \% \geq 10 \mathrm{mmHg} \\
0.8 \% \geq 15 \mathrm{mmHg} \\
0 \% \geq 20 \mathrm{mmHg} \\
5.2 \% \geq 10 \mathrm{mmHg} \\
2.6 \% \geq 15 \mathrm{mmHg} \\
0 \% \geq 20 \mathrm{mmHg}\end{array}$ \\
\hline
\end{tabular}

a Published and unpublished data; all other studies published data only. $A B I=$ ankle-brachial index.

Method of measurement

Sample size

Prevalence of

Simultaneous three pairs of

447

systolic differences

measurements

Two automated machines in $0.1 \% \geq 20 \mathrm{mmHg}$

simultaneous $2 \times 2$ crossover design

mean of four pairs of readings

364

$5.2 \% \geq 10 \mathrm{mmHg}$

$0 \geq 20 \mathrm{mmHg}$

Simultaneous four-limb machine:

ABI-form device (COLIN VP1000):

1090

9.1\% $>10 \mathrm{mmHg}$

single reading

Two Omron HEM 705CP in

simultaneous $2 \times 2$ crossover design

mean of four pairs of readings

Two Omron HEM 705CP in

simultaneous $2 \times 2$ crossover design;

mean of four pairs of readings

Mean of two simultaneous pairs of

readings with $2 \times 0$ mron M5-

automated machines

\begin{tabular}{|c|c|c|}
\hline $\begin{array}{l}\text { Two Omron HEM } 705 \mathrm{CP} \text { in } \\
\text { simultaneous } 2 \times 2 \text { crossover design; }\end{array}$ & 101 & $\begin{array}{l}10 \% \geq 10 \mathrm{mmHg} \\
4 \% \geq 15 \mathrm{mmHg}\end{array}$ \\
\hline
\end{tabular}

mean of four pairs of readings

Simultaneous Microlife WatchBP ${ }^{\circledR} \quad 118 \quad 10 \% \geq 10 \mathrm{mmHg}$

Office; mean of three pairs of

measurements

Two Omron HEM $725 \mathrm{CIC}$ automatic

sphygmomanometers, swapped after

first pair of readings; mean of two pairs

$20.7 \%>5 \mathrm{mmHg}$

$13.5 \%>10 \mathrm{mmHg}$

$1.8 \%>20 \mathrm{mmHg}$

Two pairs of simultaneous $\quad 261$ males $\quad 1.9 \% \geq 10 \mathrm{mmHg}$

measurements with 203 females $\quad 0 \% \geq 10 \mathrm{mmHg}$

$2 \times$ Omron MX3

Simultaneous four-limb measurement (COLIN waveform analyser, device not stated].

Simultaneous four-limb machine;

$6.4 \% \geq 15 \mathrm{mmHg}$

mellitus recruited from five gener

two cardiovascular risk

factors; $76 \%$ hypertensive

\begin{tabular}{cc}
111 & $20.7 \%>5 \mathrm{mmHg}$ \\
& $13.5 \%>10 \mathrm{mmHg}$ \\
& $1.8 \%>20 \mathrm{mmHg}$ \\
\hline 261 males & $1.9 \% \geq 10 \mathrm{mmHg}$ \\
203 females & $0 \% \geq 10 \mathrm{mmHg}$
\end{tabular}

Consecutive patients with type 2 diabetes

895 (60.5\%) with hypertension

$11.7 \% \geq 10 \mathrm{mmHg}$

$5.0 \% \geq 15 \mathrm{mmHg}$

repeated measures

Mean of second and third simultaneous

$4.8 \% \geq 10 \mathrm{mmHg}$

pairs of readings with four-lim

Two Omron HEM 705CP in

514 (diabetes)

$8.6 \% \geq 10 \mathrm{mmHg}$

$\mathrm{mmH}$

$2.9 \% \geq 10 \mathrm{mmHg}$

$2 \%>10 \mathrm{mmHg}$

Two Omron HEM 705CP in

265 (diabetes)

$0.8 \% \geq 15 \mathrm{mmHg}$

$0 \% \geq 20 \mathrm{mmHg}$ 
Study or subgroup

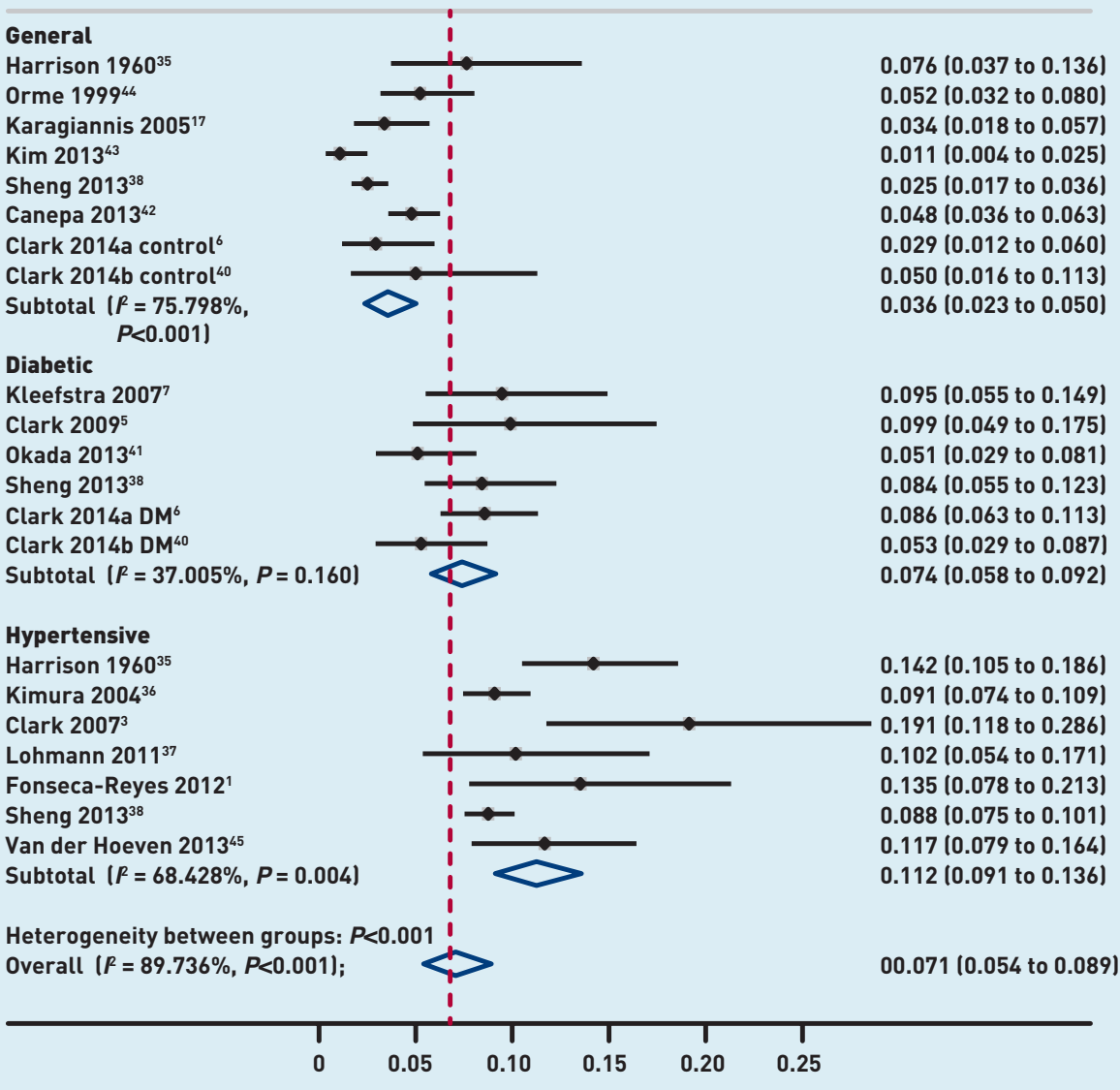

Figure 2. Prevalence of systolic inter-arm differences $\geq 10 \mathrm{mmHg}$. arm difference $\geq 10 \mathrm{mmHg}$ were $11.2 \%$ (95\% confidence interval $[\mathrm{Cl}]=9.1$ to 13.6 ) for seven populations with hypertension (3858 participants), ${ }^{1,3,35-39} 7.4 \%(95 \% \mathrm{Cl}=5.8$ to 9.2) for six populations with diabetes (1648 participants), ${ }^{5-7,38,40,41}$ and $3.6 \%$ $(95 \% \mathrm{Cl}=2.3$ to 5.0 ) for eight communitybased groups without diabetes or hypertension (3751 participants) b,17,35,38,40,42-44 $(P<0.001$ for subgroup differences; Figure 2). Substantial statistical heterogeneity

\section{Table 2. Univariable and multivariable meta-regression analyses for systolic inter-arm blood pressure differences $\geq 10 \mathrm{mmHg}$}

\begin{tabular}{|c|c|c|}
\hline Covariate & Univariable $P$-value & Multivariate model ${ }^{\boldsymbol{P}} \boldsymbol{P}$-value \\
\hline Health status ${ }^{b}$ & 0.012 & 0.509 \\
\hline Absolute systolic blood pressure & 0.041 & 1.000 \\
\hline Geography & 0.894 & 0.815 \\
\hline Mean age & 0.668 & 0.998 \\
\hline Percentage male & 0.497 & 1.000 \\
\hline Setting $^{d}$ & 0.838 & 1.000 \\
\hline
\end{tabular}

${ }^{a}$ Adjusted for multiple testing. ${ }^{b}$ Non-diabetic normotensive versus diabetic versus hypertensive. ${ }^{c}$ Country of conduct. ${ }^{d}$ Community versus clinic. $P<0.05$ significant.
$(R=76 \%)$ was observed across studies in the general population group; there was a lower prevalence for the two cohorts of East Asian origin ${ }^{38,43}$ compared with the six Western groups, which accounted for heterogeneity in the latter but not the former $(2.0 \%$ [95\% Cl $=1.4$ to 2.8$] ; /^{2}=83 \%$ versus $4.4 \%(95 \% \mathrm{Cl}=3.5$ to 5.5$) ; /^{2}=14 \%$; $P<0.001)$. Similarly, in the hypertensive population, prevalence was lower in the two East Asian cohorts $18.9 \%[95 \% \mathrm{Cl}=7.9$ to 9.9$\left.] ; \quad I^{2}=77 \%\right)^{36,38}$ compared with the remaining Western populations $113.3 \%$ $[95 \% \mathrm{Cl}=11.0$ to 15.7$] ; \quad L^{2}=6 \% ; \quad P<0.001$ (Appendix 2, available from the authors on request). The corresponding prevalences for differences $\geq 15 \mathrm{mmHg}$ were $4.0 \%$ $195 \% \mathrm{Cl}=1.9$ to 6.8$)$ in hypertension (three cohorts; 2229 participants), 2.3\% (95\% $\mathrm{Cl}=1.1$ to 3.9 ) in diabetes (four cohorts; 1165 participants), and $0.7 \%(95 \% \mathrm{Cl}=0.1$ to 1.5) without diabetes or hypertension (five cohorts; 2941 participants; $P=0.004$ for subgroup differences). Prevalences were again lower for the one study of a Chinese population compared with the remaining Western cohorts. For differences $\geq 20 \mathrm{mmHg}$, prevalences were $1.0 \%(95 \% \mathrm{Cl}=0.6$ to 1.5$)$ (three cohorts; 2229 participants), $\quad 0.4 \% \quad(95 \% \quad \mathrm{Cl}=0$ to 1.1) (four cohorts; 1165 participants), and $0.1 \%(95 \% \mathrm{Cl}=0$ to 0.4$)$ (five cohorts; 2323 participants) respectively $(P=0.001)$; no statistical heterogeneity was observed (Appendix 2, available from the authors on request).

Univariable meta-regression showed two study-level factors to be associated with mean prevalence for systolic interarm differences $\geq 10 \mathrm{mmHg}$ : health status (normotension versus diabetes versus hypertension) and absolute level of systolic blood pressure (Table 2). Each increase of $10 \mathrm{mmHg}$ in absolute systolic blood pressure was associated with a $4 \%$ $(95 \% \mathrm{Cl}=0.9$ to 4.0$)$ increase in prevalence of an inter-arm difference $\geq 10 \mathrm{mmHg}$ (Figure 3). Mean absolute systolic blood pressure increased across the health status groups (normotension $128 \mathrm{mmHg}$ (standard deviation [SD] 7.4), diabetes $139 \mathrm{mmHg}$ (SD 4.2), and hypertension $148 \mathrm{mmHg}$ (SD 17); $P=0.02$ ) indicating potential co-linearity of these two variables. Meta-regression of prevalence against health status after adjustment for absolute blood pressure was no longer significant, and no other study-level factors were found to be associated with inter-arm difference prevalence in multivariable analysis (Appendix 2, available from the authors on request). 


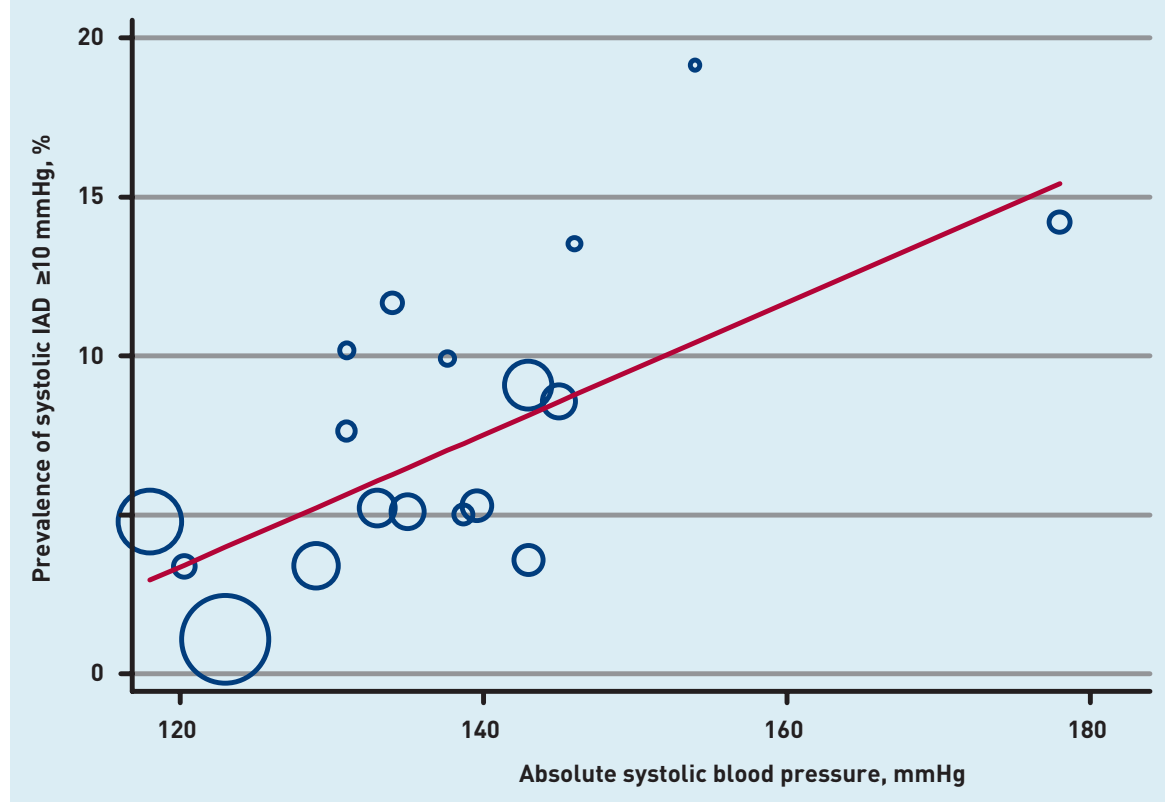

Figure 3. Study level association between mean systolic blood pressure and prevalence of systolic inter-arm differences $\geq 10 \mathrm{mmHg}$.

Figure 4. Funnel plot for prevalence of systolic interarm differences $\geq 10 \mathrm{mmHg}$.
Five studies reported both simultaneously and sequentially measured prevalence data for systolic inter-arm differences $\geq 10 \mathrm{mmHg}$. ${ }^{7,35,37,42,45}$ Pooled analysis of data after adjustment for the paired nature of the data gave a prevalence of $6.4 \%(95 \% \mathrm{Cl}=5.0$ to 7.8$)$ for measurement by a simultaneous method compared with $14.6 \%(95 \% \mathrm{Cl}=12.5$ to 16.6 ; $P<0.001$ l) for a sequential method; and a relative risk (RR) for diagnosis of an inter-arm difference by sequential compared with simultaneous measurement of $\geq 10 \mathrm{mmHg}$ of $2.2(95 \% \mathrm{Cl}=1.1$ to 4.5$)$. Statistical heterogeneity between studies $\left(/^{2}=85 \%\right)$ was explained by a single study

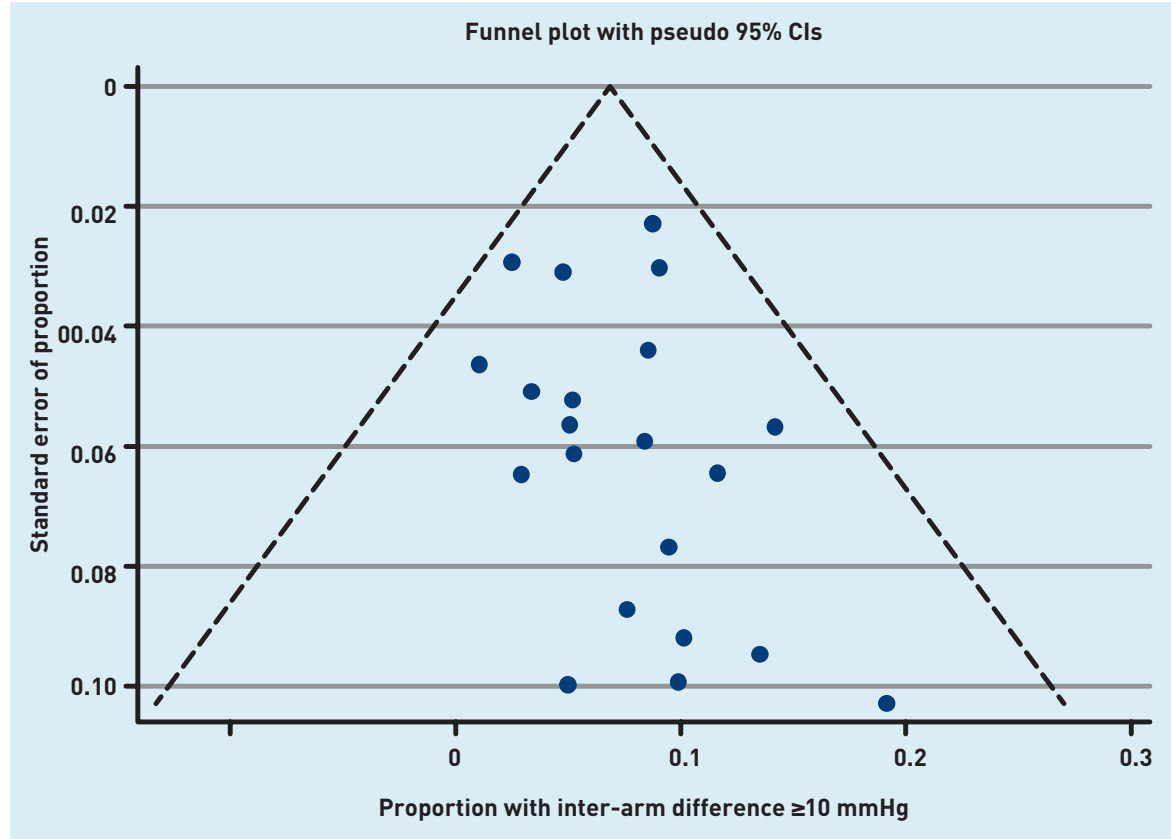

that reported a higher prevalence of interarm differences for simultaneous compared with sequential measurements, ${ }^{42}$ whereas all other studies reported lower prevalences for simultaneous measurements. This outlying study result was based on averaging the second and third pairs of readings, but sequentially measured prevalences were higher than simultaneous for each of the three individual pairs of measurements made. Sensitivity analysis by substituting the non-averaged data for this study accounted for the statistical heterogeneity (residual $\left.I^{2}=37 \% ; P=0.17\right) ;$ the resulting RR was 2.9 $(95 \% \mathrm{Cl}=2.1$ to 4.1$)$.

Visual inspection of funnel plots suggested no publication bias through missing small studies reporting low inter-arm difference prevalences (Figure 4), and the Egger tests were not significant $(P$-values $=0.32$, 0.26 , and 0.75 for inter-arm differences $\geq 10 \mathrm{mmHg}, \quad 15 \mathrm{mmHg}$, and $20 \mathrm{mmHg}$ respectively (Appendix 2, available from the authors on request).

\section{DISCUSSION}

\section{Summary}

This systematic review and meta-analysis presents a contemporary synthesis of estimates of the prevalence of systolic interarm differences in populations relevant to primary care. The prevalences of inter-arm difference rise in relation to cardiovascular comorbidity (such as diabetes and/or hypertension) in the population studied for all chosen cut-off values, and comparison with paired sequentially measured differences confirms that prevalence can be overestimated threefold when a simultaneous measurement method is not employed.

\section{Strengths and limitations}

This study builds on the authors' previous reviews. ${ }^{2,20}$ The search terms are intentionally broad and therefore it is unlikely that important publications relevant to this review have been missed. The searches were supplemented with an author's archives, contacts, and peer review activity. ${ }^{46,47}$ This meta-regression demonstrated the univariable association of rising absolute blood pressures and increasing inter-arm difference prevalences. This association did not persist on multivariable regression; however, there was co-linearity of blood pressure with clinical status. Given the relatively small number of included studies, these multivariate meta-regression analyses were potentially underpowered.

\section{Comparison with existing literature}

The prevalence figures reported here are 
lower than those previously reported in a previous study of hypertension 1 19.6\% $\geq 10 \mathrm{mmHg} \quad[95 \% \quad \mathrm{Cl}=18.0$ to 21.3$]]^{2}$ however, only four studies met that study's inclusion criteria in 2006, 23,35,44,48 and until recently there was a paucity of data truly representative of general community populations measured by simultaneous methods. ${ }^{6}$ There has been a rapid expansion of interest in inter-arm difference over the last decade; ${ }^{49}$ half of the 16 studies contributing to this review were published within the last 4 years. ${ }^{1,6,38,40-43,45}$ A number were included in the recent review by Singh and colleagues which confirmed that prevalence rates are lower for communitybased cohorts compared with hospital data; ${ }^{25}$ that review reported a community prevalence for systolic differences $\geq 10 \mathrm{mmHg}$ of $7.5 \%(95 \% \mathrm{Cl}=5.6$ to 9.4$)$. However, their findings were based on only four cohorts, $36,38,42,50$ of which one study included $50 \%$ subjects with hypertension, ${ }^{36}$ another reported a mixed population (the lead author of which has provided additional subgroup data for the analyses reported here), ${ }^{38}$ and the third did not meet the inclusion criteria because it did not report repeated simultaneous measurements. ${ }^{50}$ Furthermore three studies from the authors' own research group were misclassified in that review as outpatient studies and excluded from community prevalence analyses, despite correspondence with and provision of additional data to the review's authors. ${ }^{3,5,6}$ These factors account for the erroneously high estimate of prevalence for the general population compared with the data presented here. Singh and colleagues also stated that communitybased studies included in their review did not report data for systolic inter-arm differences $\geq 15 \mathrm{mmHg}$ or $\geq 20 \mathrm{mmHg}$; data from five such studies are included in this report. $6,35,38,40,44$

The prevalence of an inter-arm difference in hypertension is higher at any cut-off compared with the non-hypertensive population. Prevalence varies with absolute blood pressure levels ${ }^{51,52}$ and these findings of higher prevalences with, rather than without, hypertension are consistent with other reports that did not meet the inclusion criteria for this analysis. ${ }^{2,22,23,53,54}$ The prevalence figures for diabetes are intermediate between those found for normotensive non-diabetic and hypertensive populations. Inter-arm blood pressure differences are associated with peripheral vascular and cerebrovascular disease, 20,55,56 both conditions that share hypertension as a major risk factor. ${ }^{57}$ It therefore seems plausible that the prevalence of inter-arm differences, which have been described as markers of peripheralarterial disease, 10,15,58,59 rise with the baseline vascular risk of the population studied.

This study's findings suggest that prevalences of an inter-arm difference may vary by ethnicity, with lower prevalences of $a \geq 10 \mathrm{mmHg}$ difference seen both with and without hypertension for East Asian compared with Western populations. These prevalence differences were not explained by variations in systolic blood pressures between ethnic groups. Recently, in a study designed specifically to compare inter-arm difference between ethnic groups, there were no significant differences in interarm prevalences between white British, South Asian, and African Caribbean cohorts. ${ }^{60}$ However, the larger MESA (MultiEthnic Study of Atherosclerosis) study has reported higher prevalence of systolic inter-arm differences $\geq 15 \mathrm{mmHg}$ in African American and white non-Hispanic Americans compared with Hispanic or Chinese Americans. ${ }^{61}$

Few studies have directly compared simultaneous and sequential measurement techniques; the two methods appear to correlate well during a single assessment session, ${ }^{45,62}$ but not over different visits. 7.63 Studies on the reproducibility of an interarm difference over time are mainly short term (that is, weeks), ,62 apart from a small 1-year retrospective follow-up in diabetes.?

Prevalence figures have previously been shown to be higher when a sequential rather than a simultaneous measurement technique is employed. ${ }^{35,62,64}$ Pooled data in this review show a relative risk of detecting a systolic inter-arm difference $\geq 10 \mathrm{mmHg}$ of 2.9 for sequential compared with simultaneous measurement. A comparable risk ratio (2.2) was reported in a previous systematic review that compared pooled risks across different studies. ${ }^{28}$ The authors believe that these findings are the first pooled analysis of paired sequential and simultaneous measurements in the same groups of individuals, as opposed to pooled prevalence data derived from unmatched studies according to method of inter-arm measurement.

Prevalence of inter-arm difference declines with number of pairs of measurements, ${ }^{6,42,60,62}$ possibly in part due to white-coat effects on blood pressure. ${ }^{60,65}$ Verberk has estimated that an inter-arm difference $\geq 10 \mathrm{mmHg}$ is twice as likely to be observed when based on a single rather than repeated pairs of simultaneous measurements. ${ }^{28}$ Recently, devices have 
been developed that measure two or four limbs simultaneously. Four studies reporting results from a four-limb device ICOLIN VP1000 waveform analyser, Omron, Japan) are included in this analysis. 36,38,41,42 Sensitivity analyses for this device did not show different prevalence estimates for any cut-off or subgroup compared to other repeated measurement protocols. It is a sophisticated waveform analysis device and it cannot therefore be assumed that single pairs of measurements obtained by other single or paired devices do not overestimate prevalence. Two studies in this review used a simultaneous two-limb device that averages three pairs of readings (WatchBP ${ }^{\circledR}$ Office, Microlife, UK). ${ }^{37,45}$ Lohmann and colleagues found no significant differences in prevalence calculated from two or three simultaneous pairs of readings using this device, and there was no evidence of different prevalence findings based on these studies compared with other methods. ${ }^{37}$

\section{Implications for research and practice}

Systolic inter-arm differences are associated with higher prevalences of peripheral arterial disease, $, 10,20$ and with increased cardiovascular and all-cause mortality. ${ }^{19-21}$ This study's findings support the current advice in hypertension guidelines that inter-arm difference, when observed, should be confirmed with simultaneous measurement of both arms. ${ }^{26,29}$ However, detection methods in daily primary care need to be practical or they will not be adopted. ${ }^{46,66}$ It has been previously found that a single pair of sequential measurements can exclude the presence of an inter-arm difference on simultaneous measurement with good specificity and high negative predictive values $(0.97$ for $\geq 10 \mathrm{mmHg}$ and 0.99 for $\geq 15 \mathrm{mmHg}$ ), ${ }^{6}$ and is associated with increased cardiovascular and all- cause mortality. ${ }^{15}$ Therefore, a sequential method of measurement still has a role in identifying people in need of further assessment for inter-arm difference.

The prevalence figures presented here are useful to estimate how often an inter-arm difference may be missed if not checked for in primary care. For example, with a prevalence of $10 \%$, a systolic blood pressure might be underestimated by $\geq 10 \mathrm{mmHg}$ through the chance selection of the lower reading arm once in every 20 assessments, leading to false reassurance about, or undertreatment of, high blood pressure. 5,10,17,67

This study's findings quantify the prevalence of inter-arm differences that may be expected in primary care populations, suggesting that an interarm blood pressure difference occurs in a significant minority of these patients. Historically, inter-arm difference has not been routinely checked for in primary care, ${ }^{27}$ although uptake seems to be increasing (CE Clark, unpublished data, 2016) and guideline recommendations are due for review. ${ }^{68}$ Therefore, practitioners should ensure that a difference has been looked for before making treatment decisions based on blood pressure measurements. A simultaneous method of measurement is needed to confirm the presence of an inter-arm difference and this should be the method of choice for any future studies.

Further work is required to establish the validity of individual devices for accuracy of measurement based on a single pair of measurements, and further data are required to explore more fully any ethnic variations in prevalence or implications of inter-arm differences. The authors are currently conducting an individual patient data meta-analysis that will provide population-specific evidence on prevalence. ${ }^{69}$

\section{Provenance}

Freely submitted; externally peer reviewed.

\section{Competing interests}

The authors have declared no competing interests.

\section{Acknowledgements}

The authors are grateful to Prof. Jiguang Wang and Dr Niels van der Hoeven for contributing additional subgroup data from their studies, ${ }^{38,45}$ and to Prof. Nanno Kleefstra for clarifying his methods. ${ }^{7}$ Thanks are also due to Mrs Joy Choules for retrieving many of the papers included in this review.

\section{Discuss this article}

Contribute and read comments about this article: bjgp.org/letters 


\section{REFERENCES}

1. Fonseca-Reyes S, Forsyth-MacQuarrie AM, García de Alba-García JE, et al. Simultaneous blood pressure measurement in both arms in hypertensive and nonhypertensive adult patients. Blood Press Monit 2012; 17(4): 149-154.

2. Clark CE, Campbell JL, Evans PH, et al. Prevalence and clinical implications of the inter-arm blood pressure difference: a systematic review. J Hum Hypertens 2006; 20(12): 923-931.

3. Clark CE, Campbell JL, Powell RJ, et al. The inter-arm blood pressure difference and peripheral vascular disease: cross-sectional study. Fam Pract 2007; 24(5): 420-426.

4. Clark CE, Taylor RS, Shore AC, et al. The difference in blood pressure readings between arms and survival: primary care cohort study. BMJ 2012; 344: e1327.

5. Clark CE, Greaves C, Evans PH, et al. The inter-arm blood pressure difference in type 2 diabetes: a barrier to effective management? Br J Gen Pract 2009; DOI: 10.3399/bjgp09X420752.

6. Clark CE, Steele AM, Taylor RS, et al. Inter-arm blood pressure difference in people with diabetes: measurement and vascular and mortality implications: a cohort study. Diabetes Care 2014; 37(6): 1613-1620.

7. Kleefstra N, Houweling ST, Meyboom-de Jong B, et al. Measuring the blood pressure in both arms is of little use; longitudinal study into blood pressure differences between both arms and its reproducibility in patients with diabetes mellitus type 2. Ned Tijdschr Geneeskd 2007; 151(27): 1509-1514.

8. Agarwal R, Bunaye Z, Bekele DM. Prognostic significance of between-arm blood pressure differences. Hypertension 2008; 51(3): 657-662

9. Quiroga B, Galán I, Garcia de Vinuesa S, et al. Interarm systolic blood pressure as a predictor of cardiovascular events in patients with chronic kidney disease. Nephrol Dial Transplant 2015; 30(5): 801-806.

10. Aboyans V, Criqui MH, McDermott MM, et al. The vital prognosis of subclavian stenosis. J Am Coll Cardiol 2007; 49(14): 1540-1545.

11. Ray WT. Assessment of blood pressure discrepancies in third-trimester hypertensive gravidas. AANA J 2000; 68(6): 525-530.

12. Poon LC, Kametas N, Strobl I, et al. Inter-arm blood pressure differences in pregnant women. BJOG 2008; 115(9): 1122-1130.

13. Cassidy $\mathrm{P}$, Jones K. A study of inter-arm blood pressure differences in primary care. J Hum Hypertens 2001; 15(8): 519-522.

14. Clark CE, Powell RJ. The differential blood pressure sign in general practice: prevalence and prognostic value. Fam Pract 2002; 19(5): 439-441.

15. Clark CE, Taylor RS, Butcher I, et al. Inter-arm blood pressure difference and mortality: a cohort study in an asymptomatic primary care population at elevated cardiovascular risk. Br J Gen Pract 2016; D0I: 10.3399/bjgp16X684949.

16. Agarwal S. Should blood pressure be measured in both arms? [Abstract]. Chest 2012;142: 126A

17. Karagiannis A, Tziomalos K, Krikis N, et al. The unilateral measurement of blood pressure may mask the diagnosis or delay the effective treatment of hypertension. Angiology 2005; 56(5): 565-569.

18. Kulkarni PK, Shekhar S, Reddy BN, et al. Blood pressure measurement: one arm or both arm? Indian J Med Sci 2011; 65(9): 406-410.

19. Weinberg I, Gona P, O'Donnell CJ, et al. The systolic blood pressure difference between arms and cardiovascular disease in the Framingham Heart Study. Am J Med 2014; 127(3): 209-215

20. Clark CE, Taylor RS, Shore AC, et al. Association of a difference in systolic blood pressure between arms with vascular disease and mortality: a systematic review and meta-analysis. Lancet 2012; 379(9819): 905-914.

21. Clark $\mathrm{C}$, Shore A, Taylor $\mathrm{R}$, et al. The inter-arm difference in blood pressure and mortality: systematic review and meta-analysis. J Hypertens 2015; 33 Suppl 1: e11.

22. Kristensen BO, Kornerup HJ. Which arm to measure the blood pressure? Acta Med Scand 1982; 670(Suppl): 69-73.

23. Amsterdam B, Amsterdam AL. Disparity in blood pressures in both arms in normals and hypertensives and its clinical significance. N Y State J Med 1943; 43: $2294-2300$

24. Swallow RA. Hypertension: which arm? [Letter]. BMJ 1975; 3: 370.

25. Singh S, Sethi A, Singh M, et al. Prevalence of simultaneously measured interarm systolic blood pressure difference and its clinical and demographic predictors: a systemic review and meta-analysis. Blood Pressure Monitor 2015 20(4): 178-185.

26. National Institute for Health and Care Excellence. Hypertension: The clinical management of primary hypertension in adults, update of clinical guidelines 18 and 34. CG127. 2011. https://www.nice.org.uk/guidance/cg127 laccessed 23 Sep 2016).

27. Heneghan C, Perera R, Mant D, Glasziou P. Hypertension guideline recommendations in general practice: awareness, agreement, adoption, and adherence. Br J Gen Pract 2007: DOI: 10.3399/096016407782604965.

28. Verberk WJ, Kessels AGH, Thien T. Blood pressure measurement method and inter-arm differences, a meta-analysis. Am J Hypertens 2011; 24(11) 1201-1208.

29. Mancia G, Fagard R, Narkiewicz K, et al. 2013 ESH/ESC Guidelines for the management of arterial hypertension: the Task Force for the management of arterial hypertension of the European Study of Hypertension (ESH) and of the European Society of Cardiology (ESC). J Hypertens 2013; 31(7): 1281-1357.

30. Chapman JM, Clark VA, Coulson AH, et al. Problems of measurement in blood pressure surveys: inter-observer differences in blood pressure determinations. Am J Epidemiol 1966; 84(3): 483-494

31. Higgins JPT, Green S, eds. Cochrane handbook for systematic reviews of interventions version 5.1.0. The Cochrane Collaboration, 2011. http://handbook cochrane.org/ (accessed 23 Sep 2016).

32. Rao JN, Scott AJ. A simple method for the analysis of clustered binary data. Biometrics 1992; 48(2): 577-585

33. Egger M, Davey Smith G, Schneider M, et al. Bias in meta-analysis detected by a simple, graphical test. BMJ 1997; 315(7109): 629-634.

34. Zwirn P, Burnet H, Barthélémy P. Comparison between left and right humeral arterial pressure. Indirect measurement with an automatic apparatus. Ann Cardiol Angeiol (Paris) 1991; 40(4): 203-208.

35. Harrison EG, Roth GM, Hines EA. Bilateral indirect and direct arterial pressures. Circulation 1960; 22: 419-436.

36. Kimura A, Hashimoto J, Watabe D, et al. Patient characteristics and factors associated with inter-arm difference of blood pressure measurements in a general population in Ohasama, Japan. J Hypertens 2004; 22(12): 2277-2283.

37. Lohmann FW, Eckert S, Verberk WJ. Interarm differences in blood pressure should be determined by measuring both arms simultaneously with an automatic oscillometric device. Blood Press Monit 2011; 16(1): 37-43.

38. Sheng CS, Liu M, Zeng WF, et al. Four-limb blood pressure as predictors of mortality in elderly Chinese. Hypertension 2013; 61(6): 1155-1160.

39. Van der Hoeven NV, Lodestijn S, Nanninga S, et al. Simultaneous compared to sequential blood pressure measurement results in smaller inter-arm blood pressure differences. J Clin Hypertens 2013; 15(11): 839-844.

40. Clark CE, Casanova F, Gooding K, et al. Inter-arm blood pressure difference and arterial stiffness. J Hypertension 2014; 32 (eSuppl A): e30.

41. Okada H, Fukui M, Tanaka M, et al. A difference in systolic blood pressure between arms and between lower limbs is a novel risk marker for diabetic nephropathy in patients with type 2 diabetes. Hypertens Res 2013; 36(5): 403-407

42. Canepa M, Milaneschi Y, Ameri P, et al. Relationship between inter-arm difference in systolic blood pressure and arterial stiffness in communitydwelling older adults. J Clin Hypertens 2013; 15(12): 880-887.

43. Kim KB, Oh MK, Kim HG, et al. Inter-arm differences in simultaneous blood pressure measurements in ambulatory patients without cardiovascular diseases. Korean J Fam Med 2013; 34(2): 98-106.

44. Orme S, Ralph SG, Birchall A, et al. The normal range for inter-arm differences in blood pressure. Age Ageing 1999; 28(6): 537-542.

45. Van der Hoeven NV, Lodestijn S, Nanninga S, et al. Simultaneous compared with sequential blood pressure measurement results in smaller inter-arm blood pressure differences. J Clin Hypertens 2013; 15(11): 839-844.

46. Clark CE. Inter-arm blood pressure measurement needs to be practical and accurate. Am J Hypertens 2011; 24(11): 1189-1190.

47. Clark CE. Four-limb blood pressure measurement: a research tool looking for a clinical use. Hypertension 2013; 61(6): 1146-1147.

48. Lane D, Beevers M, Barnes N, et al. Inter-arm differences in blood pressure: when are they clinically significant? J Hypertension 2002; 20(6): 1089-1095.

49. Clark CE. Difference in blood pressure measurements between arms: methodological and clinical implications. Curr Pharm Des 2015; 21(6): 737-743.

50. Johansson JK, Puukka PJ, Jula AM. Interarm blood pressure difference and target organ damage in the general population. J Hypertens 2014; 32(2): 260-266.

51. Sun H, Li P, Su H, et al. The detection rates of inter-arm systolic blood pressure difference vary with blood pressure levels in hypertensive patients under antihypertensive therapy. Int J Cardiol 2014; 172(3): e419-e420. 
52. Sun H, Li P, Su H, et al. Brachial-brachial index of systolic blood pressure in the patients under anti-hypertensive therapy. Int J Cardiol 2014; 174(3): 802-804

53. Mehlsen J, Wiinberg N. Interarm difference in blood pressure: reproducibility and association with peripheral vascular disease. Int J Vasc Med 2014; 2014: 841542

54. White J, Mortensen LH, Kivimaki M, et al. Interarm differences in systolic blood pressure and mortality among US army veterans: aetiological associations and risk prediction in the Vietnam experience study. Eur J Prev Cardiol 2014; 21(11): 1394-1400.

55. Kim J, Song TJ, Song D, et al. Interarm blood pressure difference and mortality in patients with acute ischemic stroke. Neurology 2013; 80(16): 1457-1464.

56. Madan VD, Rockman CB, Guo Y, et al. Association between interarm systolic blood pressure differential and peripheral artery disease: a population database of over 3.6 million subjects [Abstract 17204]. Circulation 2013;128(Suppl 22): A17204.

57. Rapsomaniki E, Timmis A, George J, et al. Blood pressure and incidence of twelve cardiovascular diseases: lifetime risks, healthy life-years lost, and agespecific associations in 1.25 million people. Lancet 2014; 383(9932): 1899-1911.

58. Aboyans V. Asymmetrical limbs arterial pressures: a new marker of atherosclerosis. Hypertens Res 2013; 36(5): 394-395.

59. Shadman R, Criqui MH, Bundens WP, et al. Subclavian artery stenosis: prevalence, risk factors, and association with cardiovascular diseases. J Am Coll Cardiol 2004; 44(3): 618-623.

60. Schwartz C, Koshiaris C, Clark C, et al. Does the right arm know what the left arm is doing? Ethnic variations in clinical inter-arm difference and relationship to white coat effects. J Hypertens 2015; 33(Suppl 1): e7.
61. Aboyans V, Criqui MH, McClelland RL, et al. Intrinsic contribution of gender and ethnicity to normal ankle-brachial index values: the Multi-Ethnic Study of Atherosclerosis (MESA). J Vasc Surg 2007; 45(2): 319-327.

62. Eguchi K, Yacoub M, Jhalani J, et al. Consistency of blood pressure differences between the left and right arms. Arch Intern Med 2007; 167(4): 388-393.

63. Bakx JC. Blood pressure differences between left and right arms? Hart Bulletin 2007; 38(4): 109

64. Singer AJ, Hollander JE. Blood pressure. Assessment of interarm differences Arch Intern Med 1996; 156(17): 2005-2008.

65. Martin U, Holder R, Hodgkinson J, McManus R. Inter-arm blood pressure differences compared with ambulatory monitoring: a manifestation of the 'white-coat' effect? Br J Gen Pract 2013; DOI: 10.3399/bjgp13X663055.

66. Carlsen B, Glenton C, Pope C. Thou shalt versus thou shalt not: a metasynthesis of GPs' attitudes to clinical practice guidelines. Br J Gen Pract 2007; 57(545): 971-978.

67. Banks MJ, Erb N, George P, et al. Hypertension is not a disease of the left arm: a difficult diagnosis of hypertension in Takayasu's arteritis. J Hum Hypertension 2001; 15(8): 573-575.

68. Hawkes N. Sixty seconds on ... measuring blood pressure. BMJ 2016; 353: i2626.

69. Clark C, Campbell J, Boddy K, et al. Inter-arm blood pressure difference, cardiovascular events, cerebrovascular disease and mortality: an individual patient data meta-analysis. PROSPERO 2015: CRD42015031227. http://www. crd.york.ac.uk/PROSPERO/display_record.asp?ID=CRD42015031227 laccessed 23 Sep 2016). 


\section{Appendix 1. Search strategy}

\section{Number Database}

Embase, MEDLINE, CINAHL Embase, MEDLINE, CINAHL Embase, MEDLINE, CINAHL Embase, MEDLINE, CINAHL Embase, MEDLINE, CINAHL Embase, MEDLINE, CINAHL Embase, MEDLINE, CINAHL Embase, MEDLINE, CINAHL Embase, MEDLINE, CINAHL Embase, MEDLINE, CINAHL

\section{Search term}

(subclavian AND stenosis).af

(blood AND pressure AND NEAR AND difference).af

(blood AND pressure AND NEAR AND differential).af

(interarm AND NEAR AND differential).af

(interarm AND NEAR AND difference).af

(inter-arm AND NEAR AND difference).af

(inter-arm AND NEAR AND differential).ti,ab

linter AND arm AND NEAR AND differentiall.af

(inter AND arm AND NEAR AND difference).af

1 OR 2 OR 3 OR 4 OR 5 OR 6 OR 7 OR 8 OR 9 